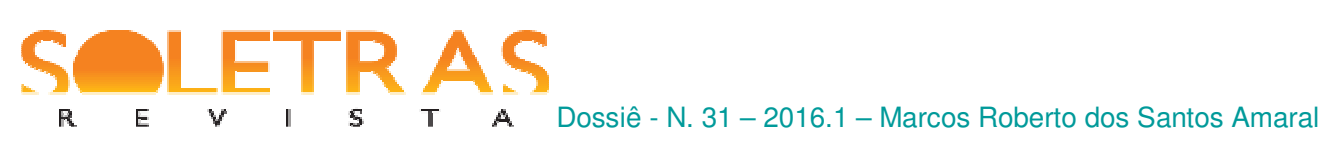

\title{
A impolidez como princípio constitutivo dos jogos de linguagem: o sentido parcial e violentamente compartilhado
}

\author{
Marcos Roberto dos Santos Amaral ${ }^{1}$ \\ Secretaria de Educação do Ceará
}

\begin{abstract}
Resumo: Neste artigo, aproximando-nos de posicionamentos políticos contra-hegemônicos e desconstrutores em estudos críticos da linguagem, e contrapondo-nos à falaciosa crença em práticas discursivas construídas harmoniosamente para o bem comum, problematizamos o princípio da cooperação de Grice, justamente por envolver uma visão de mundo liberal, marcado pelo consumo de uma ideia de simetria de relações de poder. Analisamos a polêmica on-line entre o blog "Não Me Kahlo" e um comentador a respeito da expressão "mulheres do grelo duro", de Lula. Fundamentamo-nos nestes autores, conceitos e categorias: Leezenberg (2014), impolidez constitutiva do discurso; Rajagopalan (2010, 2014), o caráter político dos estudos da linguagem; Silva, Alencar e Martins Ferreira (2014), síntese do princípio da cooperação; Bloomaert (2014) e Rajagopalan (2014), poder e ideologia na linguagem; Bakhtin/Voloshnov (2010) cadeia ideológica, horizonte social e discurso como arena de lutas ideológicas; e Alencar (2014) e Gonçalves (2014), desdobramentos da institucionalidade da autoridade dos atos de fala. Metodologicamente, criticamos a consensualidade como norma nos jogos de linguagem, apontando o caráter negador e de coação da fala no evento estudado. Concluímos que o caráter particularmente desagregador do ato de fala polêmica comentador/“Não Me Kahlo" exemplifica a emulação entre os enunciadores e que esta, no discurso, não é um ato anômalo, ou incomum. Assim, defendemos que o princípio da cooperação não é o único fundamento nas práticas discursivas de construção de sentido e talvez mesmo nem seja o mais produtivo, pois há casos em que o significado é disputado, recorrendo-se à impolidez nos jogos de linguagem.
\end{abstract}

Palavras-chave: Impolidez. Ideologia linguística. Práticas discursivas. Violência. Feminismo.

\section{Introdução}

Notadamente, os estudos críticos da linguagem constituem-se atravessados por, no mínimo, três grandes viradas, a saber: a virada linguística na filosofia (WITTGENSTEIN, 1989; AUSTIN, 1990), a virada política na pragmática (RAJGOPALAN, 2010) e a virada prática nos estudos sociais (LEEZEMBERG, 2014). Todas estas viradas fundam-se enquanto perspectiva de análise da linguagem orientada pelas práticas contextuais político-ideológicas imediatas e amplas. Em outras palavras, as viradas nos estudos da linguagem reconheceram o

1 Professor efetivo da rede estadual de ensino do Ceará - Secretaria da Educação Básica do Ceará - SEDUC-CE, desde 2010, atualmente licenciado para estudos. Mestrando do Programa de Pós-Graduação em Linguística Aplicada da Universidade Estadual do Ceará - PosLA - UECE. Bolsista da Fundação Cearense de Apoio ao Desenvolvimento Científico e Tecnológico - FUNCAP. 
caráter constitutivo do contexto concreto da significação. Esta perspectiva redefiniu os fundamentos ontológicos e epistemológicos da linguística aplicada e os estudos críticos da linguagem. É certo, pois, que a virada linguística na filosofia rompe com o paradigma de que a linguagem é representação do mundo, tratando-a como "forma de atuação sobre o real, e portanto de constituição do real” (MARCONDES, 2010, p. 10); já a virada política na pragmática, busca na "transição de um componente 'da' linguística para uma perspectiva 'de/sobre linguística (...), repensar o papel mesmo da sociedade ao moldar e manter a linguagem" (RAJAGOPALN, 2010, p. 40-1); por fim, a virada prática, em inserir os estudos da linguagem, na chamada teoria da prática (LEEZENBERG, 2014, p. 45), expõe "as limitações da suposição acrítica da agência autônoma e racional (...) e questiona a validade universal da frequentemente assumida visão de linguagem como contrato social" (ibidem, p 64). Assim, alguns princípios tradicionais tomados como inquestionáveis vão sendo postos à prova, como a questão ética. Isso ocorre, por exemplo, com o princípio semântico-formal da cooperação da linguagem de Grice.

Neste artigo, justamente, defenderemos que o princípio da cooperação não é o único fundamento nas práticas discursivas dos diversos jogos de linguagem (WITTGENSTEIN, 1989) de construção de sentido e talvez mesmo nem seja o mais produtivo. Para tal, tomaremos como objeto um post do blog "NÃO ME KHALO" que responde a uma provocação de um comentador, que polemiza o silêncio do blog diante de uma dita ofensa contra as mulheres, feita por Lula, adjetivando as mulheres de seu partido de "grelo duro". Fundamentamo-nos em Leezenberg (2014), com sua sugestão de impolidez constitutiva do discurso e não anômala deste; em Rajagopalan (2010, 2014), por propor o caráter político dos estudos da linguagem; em Silva, Alencar e Martins Ferreira, pensando em sua síntese do princípio da cooperação; além de Bloomaert (2014) e Rajagopalan (2014), a respeito da questão do poder e ideologia na linguagem. Tangenciaremos, ainda, Bakhtin/Voloshinov, quando tratam das lutas ideológicas no discurso, e Alencar (2014) e Gonçalves (2014) com seus desdobramentos da institucionalidade da autoridade dos atos de fala. Iniciaremos nossa análise comentando o princípio da cooperação segundo as máximas conversacionais postuladas pelo filosofo da linguagem Grice. Então, elucidaremos o problema da ideologia dos conceitos linguísticos, ao passo que explanaremos sobre as considerações de Leezenberg (2014) sobre a impolidez na linguagem. Em seguida, faremos uma crítica da ideologia e modelo de sociedade subjacente neste princípio. Logo, passaremos a refletir sobre nosso objeto, cuja leitura nos permite concluir sobre a impolidez como também constitutiva do 
discurso na determinação do sentido, por estar inserido em cadeias ideológicas tensas e violentas. Por fim, enfatizaremos a importância política desta perspectiva.

\section{O princípio da cooperação e a impolidez e suas consequências políticas}

Silva, Alencar e Ferreira (2014) apresentam, assim, as máximas conversacionais:

1. seja tão informativo quanto for requerido (máxima da quantidade);

2. seja verdadeiro (máxima da qualidade);

3. seja relevante (máxima da relação);

4. seja claro, breve, ordenado, não ambíguo e não obscuro (máxima do modo). (GRICE, 1982, p. 86-89, apud SILVA; ALENCAR; MARTINS FERREIRA, 2014, p. 21).

À guisa de arremate dessas máximas, Grice observa que se deve fazer uma “contribuição conversacional tal como é requerida, no momento em que ocorre, pelo propósito aceito ou direção da troca conversacional em que você está envolvido (GRICE, 1989, p. 26, apud ibidem, p. 21-2). Nestes termos, o filósofo postula o princípio da cooperação. Podemos apontar que o problema do princípio da cooperação e das máximas conversacionais está no fato de se desconsiderar que as práticas públicas estão atravessadas por "cooperação e conflito, negociação e contestação, bem como relações de poder que podem (ou não) ser percebidas como legítimas" (LEEZENBERG, 2014, p. 48). Isto é, as relações de sentido neste modelo é um produto racional e polido. Sendo assim, todas as particularidades de antagonismo e tensão específicas das práticas sociais são postas para fora dos interesses e métodos de análise. A linguagem é significada como neutra e ingênua, consequentemente, tal entendimento implica uma visão de mundo, senão também neutra e ingênua, entendida e apresentando-se como se o mundo o fosse. Porquanto, nessas explicações linguísticas e nas suas construções metalinguísticas são negligenciadas "as tortuosidades da vida, como se as atividades humanas não fossem regidas pelo capricho, pela temeridade, pelo oportunismo" (RAJAGOPALAN, 2014, p. 12), o que pode esvaziar o comprometimento ético-político do linguista.

A fim de demonstrar quanto que o conflito e a impolidez são constitutivos da prática discursiva, Leezenberg (2014) elucida a respeito da possibilidade de a interação linguística dar-se não na aceitação para a conversação, mas na sua negação. No caso, faz uma análise de diversas passagens de tragédias clássicas sofocleanas, cuja encenação ocorre quando a 
conversação é negada ou decorre de tratos impolidos; em outras palavras: é não cooperada. Exemplifica-o apontando que "protagonistas clássicos repetidamente recusam-se a participar da conversação e, quando o fazem, frequentemente, disputam a sinceridade, o respeito e, até mesmo, o bom senso do parceiro da conversação" (LEEZENBERG, 2014, p. 56). O autor indica que, em enunciados trágicos, há "formas de falar específicas, socialmente constituídas e diferenciadas pelas relações de poder, que sempre podem ser negociadas e desafiadas" (ibidem, p. 57). Além de que, no pensamento trágico, a linguagem "é vista não como um contrato que regula o mundo, mas sim como uma arma para transformá-lo" (ibidem, p. 61). Todos os exemplos ratificam "a eficácia social e o caráter possivelmente conflitivo da linguagem" (ibidem, p. 63).

Com efeito, o princípio da cooperação necessariamente não corrobora que todos os falantes em seu discurso são sempre "cooperativos, mas sim que eles interpretam os enunciados uns dos outros como sendo cooperativos, o que dá no mesmo" (ibidem, p. 50). Politicamente, as consequências são desastrosas, pois "esse princípio meramente captura um modo alegadamente neutro ou normal de fala" (ibidem). Defender uma visão de mundo acrítica eticamente compromete o posicionamento político dos estudiosos da linguagem em meio às demandas transformadoras das relações sociais, que atuam no sentido de impedir, ou pelo menos atenuar, que se reproduzam estruturas assimétricas de poder. É certo que o princípio da cooperação de Grice "é produto da ideologia linguística liberal, segundo a qual 'o foco da ação é a intenção individual de atores discretos, não as relações sociais das quais essas ações emergem e nas quais, retroativamente, ingressam' (KEANE, 2009, p. 55)" (SILVA; ALENCAR; MARTINS FERREIRA, 2014, p. 23). A implicação disso é que:

Uma vez que alguém adere impensadamente a esse suposto modelo universal de comunicação pragmática, está comprando, acriticamente, todo um conjunto de suposições não apenas sobre os papéis da ação social e dos falantes na determinação do significado, mas também e, principalmente, sobre sua vocação social e humana. (ibidem).

A vocação social e humana, acreditamos poder assim encenar, é para a transformação social, isto é, devemos, dentro do possível, posicionarmo-nos contra as relações de poder assimétricas e as formas de reprodução de hierarquias marginalizadoras e formas de violência social. No caso dos estudos críticos da linguagem, em especial da nova pragmática (RAJAGOPALAN, 2010), devemos fazer frente contra as visões de mundo naturalizadoras de conflitos sociais engendradas na e pela linguagem através de sua metalinguagem específica, e contra discursos e metadiscursos neutralizadores das formas antagônicas constituintes das 
práticas sociais. Esta postura é uma forma de afirmação de posições contra hegemônicas, através da crítica de encenações discursivas, já que, nelas, a disputa pelo poder é constitutiva dos sentidos estabelecidos discursivamente. Note-se que:

O poder, no entanto, em comunicação e em outras dimensões da vida social, não precisa ser legitimado, mas deve ser contestado e disputado. O poder não é necessariamente uma força puramente negativa, que distorce a comunicação genuína (i.e., cooperativa e igualitária). O poder, de fato, pode ser produtor de significados (Cf. LEEZENBERG, 2002; 2014, p. 49).

Conforme Bloomaert, portanto, "o poder exclui e inclui, produz prestígio e estigma, constrói e destrói” (2014, p. 67). Destarte, os estudos linguísticos sejam em suas formas aplicadas e pragmáticas ou em outras podem reconhecer que cada conclusão, formulação, apreciação linguística e asseveramento metadiscursivo, encerram uma ideologia linguística particular, em cujas "crenças, ideias, visões e percepções sobre linguagem e comunicação" (ibidem, p. 68) são erigidos significados que serão desempenhados concretamente e regimentarão retroativamente práticas sociais estabilizadoras e conformadoras, pois:

As pessoas produzem semiose (comportamento simbólico significativo) como performance e o fazem dentro de um campo regimentado no qual as ideologias linguísticas produzem estabilidade e capacidade de reconhecimento. (...) Elas [as ideologias linguísticas] são práticas. (ibidem, p. 69).

Assim, a relação entre forma linguística e estrutura social é mediada por ideologias linguísticas (ibidem, p. 75), de sorte que, por meio de sua análise, pode-se detectar por quais caminhos a linguagem e as práticas sociais estabelecem sua interconstituição. Por isso, toda prática metapragmática molda o contexto no qual ela caminha (ibidem, p. 76). Consequentemente, antes de se fazer qualquer defesa de uma posição linguística, deve-se fazer a crítica sobre qual perspectiva de mundo se está orientando e, mais, sobre qual mundo se pode constituir tal perspectiva de análise. Portanto, neste artigo, ao propormos a problematização de que o princípio da cooperação não é totalmente fundante dos jogos de linguagem, questionando, então, se não seja mesmo a impolidez mais produtiva, estamos problematizando do mesmo modo as visões ideológicas de mundo que subjazem à ideologia linguística liberal deste princípio. Nesta tarefa, buscaremos, portanto, não perder de horizonte as especificidades tensas das relações discursivas em que diversos antagonismos emergem e instituem performances, sem o conhecimento das quais não nos poderemos voltar contra o abuso, a marginalização e a violência que constituem as práticas discursivas. 
Leezenberg (2014) critica, com efeito, o princípio formalista da cooperação linguísticocomunicativa fundamentalmente, porque "esse princípio não é, de maneira nenhuma, universalmente presente na comunicação como frequentemente é assumido" (2014, p. 50) e porque negligencia a prática social, uma vez que:

Uma abordagem orientada para a prática, nestes termos, não apenas iria incorporar formas esperadas de comportamento que não são completamente determinadas pela consciência, pela intenção ou pelo cálculo estratégico, mas também possibilitaria mais espaço para analisarmos o conflito tão presente na comunicação. Mais importante ainda, essa abordagem ofereceria uma explicação das relações de poder na ação social, apontando, assim, para uma alternativa metodológica à imagem quase onipresente da comunicação linguística como uma troca totalmente cooperativa entre agentes racionais e autônomos (LEEZENBERG, 2014, p. 54).

A sugestão de Leezenberg de uma abordagem orientada pela prática é informada pela noção de hábitus linguístico, que, acordando com Bourdieu, consiste em "um conjunto de disposições internalizadas, semiconscientes e semi-intencionais que fazem com que os sujeitos se comportem de certas maneiras e não de outras" (ibidem, 2014, p. 52). O autor valese da virada prática dos estudos das ciências sociais para evidenciar a importância dela para os estudos da linguagem no sentido de revisar grandes problemas destes, tal qual o problema da agência e estrutura. Contra o qual lança mão de dois argumentos:

1. Na teoria linguística, assim como nas ciências sociais, há espaço para uma noção de prática que não é logicamente posterior ou metodologicamente secundária à estrutura ou à agência, mas que, ao contrário, é constitutiva de ambas; 2. Além disso, as práticas linguísticas não precisam ser, pelo menos não completamente, cooperativas. (ibidem, p. 45).

A dicotomia estrutura e agência, inclusive, é chamada para estabelecer os limites tradicionais entre semântica e pragmática, cabendo à primeira as preocupações com aquela, e à pragmática, com a outra. Tal divisão e conceituação pauta-se em três procedimentos metodológicos, segundo Leezenberg: "1. individualismo metodológico; 2. uma oposição quase estruturalista entre o comportamento individual da linguagem e o sistema da língua; 3 . uma visão consensual da comunicação" (ibidem, p. 46). Esta metodologia resolve-se por desconsiderar justamente as particularidades complexas da prática social, que não pode ser vista redutoramente como neutra e pacífica. Em decorrência disso, os enunciados não cooperativos são "tratados como meros desvios de determinada norma" (ibidem, p. 57). Esse tipo de posicionamento endossa visões de mundo ingênuas e por isso mesmo conservadoras, nas quais o conflito de poder sequer é tomado como constitutivo das práticas discursivas, quando não é totalmente negligenciado, do que, como corolário, performativamente, temos 
uma análise acrítica e descompromissada socialmente, uma vez que o objeto linguístico passa a ser idealizado e abstraído do uso concreto, o que não dá "espaço para qualquer consideração ética ou política" (RAJAGOPALAN, 2014, p. 108). A língua, portanto, torna-se meramente um artefato (BLOOMAERT, 2014, p. 71; SILVA; ALENCAR; MARTINS FERREIRA, 2014, p. 35).

\section{Coação e negação da fala e institucionalização da autoridade/marginalidade nos jogos de linguagem}

Para nossa análise, tomamos uma polêmica on-line nestes termos: ocorreu que, em uma conversa grampeada de Lula com o ex-ministro Paulo Vannuchi, gravada na terça-feira, 5/4/16, pela Polícia Federal, o ex-presidente categorizou integrantes mulheres do PT como "mulheres do grelo duro". Como esperado, o ato de fala desencadeou diversas respostas, das mais variadas entonações, da maioria das quais, podemos dizer, oscila antagonicamente entre horizontes sociais rivais, por exemplo, os axiologicamente indiciados como "direita" e "esquerda". Os atores dos extremos dessa arena de luta (BAKHTIN/VOLOSHINOV, 2010, p. 47) discursiva disputam a legitimidade de suas posições em detrimento da dos outros de quem discordam, buscando expulsá-los da ágora comunicável (BRIGGS, 2007, apud, SILVA e ALENCAR, 2014, p. 272-3). Ordinariamente, em cuja linguagem as cerimônias de polidez pouco podem regular diante de interações verbais tensas, estes contendores políticos recorrem basicamente a significados e ethos institucionais (GONÇALVES, 2014, p. 313) que desautorizam e/ou distorcem o interlocutor e o enunciado do outro, numa clara demonstração de não cooperação "conversacional”/discursiva. Dessa forma, a impolidez, o dissenso e a emulação, conforme Leezenberg (2014, p. 63) propõe, são marcas constitutivas de práticas discursivas na linguagem, como neste caso. Sobremaneira, porque o significado compartilhado foi disputado recorrendo-se à negação da fala a outrem, bem como pela coação dela mesma, o que caracteriza atos de fala violentos como constitutivos das disputas discursivas. Vejamos.

A própria origem da contenda já é um ato violento por, embora autorizada legalmente, a violação do sigilo telefônico, seu conteúdo ter sido vazado para domínio público indiscriminadamente. Por conta do que, todos os sentidos que, por ventura, tivessem sido negociados na ocasião, foram ressignificados em outros contextos. Há aí uma obliteração do lugar (SILVA e ALENCAR, 2014, p. 262) contextual original, ou seja, o contexto habitual. 
Este, então, foi deslegitimado em função dessa perda de contexto (BUTLER, 1997, p. 4, apud SILVA e ALENCAR, 2014, p. 261), por não se saber de qual contexto se está ancorado para poder reclamar tal ou qual significado compartilhado. Depois, a própria organização metapragmática desta conversa é marcada pela assimetria de poder da fala. Como se vê a seguir:

\begin{abstract}
Lula: Alô
Vannuchi: Fala, chefe.

Lula: Você ficou de me dar um retorno.

Vannuchi: Então, eu avisei para ele agora e o que aconteceu é que liguei no contato e soube que ele estava na UTI, situação grave, porque é respiratória, não dá pra falar direito. Não é uma situação grave de risco de vida, é o tal do enfisema. Aí eu falei com o genro, que também é da área, conhece. Primeiro eu perguntei ao genro se ele tinha uma condição de diretamente falar com a pessoa e ele respondeu que não. Não tenho contato, tem que ser com ele mesmo. Amanhã eu vou visitá-lo. Na hora que vi o recado do Moraes pra eu ligar, eu liguei pra ele e ele falou que tá indo daqui a pouco, já leu nos jornais, já sabe do que se trata e vai perguntar para ele. Você acha que ele tem condição de nessas coisas, canudo no nariz, telefonar, eu vou ver lá, vou
\end{abstract} sentir.

Lula: Tira o canudo por 30 segundos, caralho.

Vannuchi: Então, eu vou nessa expectativa e te dou uma resposta ainda hoje.

Lula: Sabe qual é a nossa ação.

Vannuchi: Sei.

Lula: Aquele filho da puta daquele procurador antes de dar a notícia da intimação na quinta-feira para o advogado deu pra Globonews. É um filho da p*** mesmo.

Vannuchi: Ativista político, coxinha.

Lula: O problema é o seguinte, Paulinho. Nós temos que comprar essa briga. Eu sei que é difícil, sabe. Às vezes fico pensando até se o Aragão devia cumprir um papel de homem nessa porra. O Aragão parece nosso amigo, parece, parece, parece, mas tá sempre dizendo olha... sabe.

Vannuchi: É. O pessoal tá assustado.

Lula: Nós vamos pegar esse de Rondônia agora e vamos botar a Fátima Bezerra e a Maria do Rosário em cima dele.

Vannuchi: Isso mesmo.

Lula: Sabe, porque... até a Clara Ant (...) porque fica procurando o que fazer. Faz um movimento da mulher contra esse filho da puta. Porque ele batia na mulher, levava ela pro culto, deixava ela se fuder, dava chibatada nela. Cadê as mulheres de grelo duro do nosso partido?

Vannuchi: É isso aí. Sua fala foi muito boa (EXTRA DIGITAL, 2016).

O significado de assimetria de poder nesta fala é contextualizado sequencialmente (MEY, 2014): pelo vocativo "chefe"; a cobrança de ato de fala de retorno a algo previamente acordado/devido "Você ficou de me dar um retorno"; a exigência/verificação do conhecimento apropriado da situação/performance "Sabe qual é a nossa ação"; o recurso ao palavrão por parte do enunciador Lula; e o elogio servil por parte de seu interlocutor "Sua fala foi muito boa". 
Certamente, todas essas particularidades são encenações de uma performance significada pela cobrança de um "chefe" para com seu subordinado, e não a conversa amigável entre parceiros, o que por si só já corroboraria "o argumento de que há áreas significativas da comunicação linguística que não podem ser simplesmente tomadas como cooperativas, consensuais e polidas" (LEEZENBERG, 2014, p. 63).

É digna de nota, também, a declarada intenção de ação de tirar “o canudo [possivelmente, tubo respiratório] por 30 segundos" de um doente em UTI. Isto numa ênfase (a interjeição caralho) que mostra a impaciência e tensão da fala dos interlocutores, que estão num contexto abertamente de disputa de poder político, território em que tempo e piedade são postos na lata de lixo da cortesia, de onde, pragmaticamente falando, a impolidez discursiva também advém. Nesse contexto, portanto, o sucesso político depende, em parte, da felicidade (AUSTIN, 1990, p. 29) do ato de fala do "contato". Tal característica de avizinhamento de coação de fala é regimentada pelos fundamentos da linguagem que costumeiramente são erigidos de um território constituído de violência e impolidez.

Para além das particularidades do evento "conversa grampeada de Lula e Vannuchi" espetacularizado pela grande mídia, outros atores sociais inscreveram-se nesta cadeia ideológica (BAKHTIN/VOLOSHINOV, 2010, p. 34) de interações verbais donde os variados significados foram erigidos mesmo sem o intencionarem (AUSTIN, 1990, p. 93, 96) previamente. Alguns internautas propensos ao lado dos que não simpatizam com alguns movimentos político-populares como o feminismo, ao tomarem conhecimento do "as mulheres de grelo duro do nosso partido" de Lula/Vannuchi (agora de Lula/Vannuchi/comentadores/blogueiros/nós), posicionaram-se carregando o signo de valores ofensivos às mulheres, a partir do que, orientados em outro contexto de embate discursivo (a legitimidade do feminismo e do blog "Não Me Kahlo") intimaram em posts comentários neste blog que este mesmo se manifestasse diante do que Lula havia falado. Tal ato provocou uma resposta do blog, de onde tiramos o excerto:

Olha, vou te falar uma coisa... 99,9\% das vezes que algum machista vem me falar - pelo twitter, principalmente - algo como "NÃO VAI FALAR NADA DISSO? HIPÓCRITAS!", eu não faço a mínima ideia do que ele está falando. Acho que ele pressupõe que eu faço parte do grupinho deles onde algum tipo específico de informação rola (do tipo que só tentam deslegitimar o feminismo) e, por isso, eu tenho que estar a par de tudo que está acontecendo no mundo. Daí quando vejo do que realmente se trata tenho uma preguiça enorme de realmente me manifestar. Normalmente é algo de uma idiotice sem tamanho. (...) A intenção deles não é - nem nunca foi - de um interesse legítimo em não ofender mulheres, muito menos mulheres feministas. Aliás, o que mais fazem é nos ofender. O objetivo, tal como 
Lula, era mobilizar o movimento feminista com motivação em interesse próprio. Neste caso, o objetivo era manchar a imagem do Lula. Em ambos os casos se tenta o mesmo: usar o movimento feminista como massa de manobra. E isso é de longe muito pior que falar que mulheres tem "grelo duro". O movimento feminista sempre se pautou pelo posicionamento político. Ser feminista significa incessantemente fazer política. No entanto, não nos escutam quando falamos nos direitos das mulheres, na configuração sistêmica do machismo, no feminicídio, na morte de mulheres transexuais, entre tantas outras pautas urgentes que lidamos diariamente. O que chama atenção e querem nos ouvir é sobre "grelo duro" ser ofensivo ou não? Me poupe! (LEÃO, 2016).

A tensão entre atores de grupos sociais antagônicos demarca-se, sequencialmente, pelo qualificativo "machistas", no ato de fala entoado, pejorativamente e em contraste com o enunciador feminista, e pela referência a "grupinhos". A impolidez, por sua vez, constitui a fala no sentido de ser uma resposta não espontânea, mas forçada pelo apelo provocativo de um comentador do blog "algum machista vem me falar - pelo twitter, principalmente - algo como 'NÃO VAI FALAR NADA DISSO? HIPÓCRITAS!’. Não havendo mesmo interesse cooperativo em fazer a resposta "tenho uma preguiça enorme de realmente me manifestar. Normalmente é algo de uma idiotice sem tamanho". A relação conflituosa entre os interlocutores encena-se pelos epítetos indexicalizados injuriosamente "HIPÓCRITAS!", “idiotice sem tamanho", "Me poupe!”. Neste caso, o que constitui a impolidez do ato de fala é a coação à fala e a violenta tentativa de deslegitimação da fala do outro, através da quebra do contexto de fala costumeiro, no qual os sentidos pretendidos são estabelecidos. Isto é, a autoridade da fala de "Não Me Kahlo" em nome do feminismo é que foi posta em questão, não a ponderação do ato "mulheres de grelo duro". De fato, o poder institucional é determinante na construção social dos significados (ALENCAR, 2014, p. 94; GONÇALVES, 2014, p. 313) compartilhados nos jogos de linguagem das diversas cadeias ideológicas, por isso mesmo que a impolidez discursiva decorre neste evento, posto que se questiona: “QUANDO É O LULA VOCÊS VÃO PASSAR PANO, É?!” ou "SE FOSSE O BOLSONARO VOCÊS TAVAM FALANDO ALGUMA COISA”. "Quando as pessoas vem cobrar posicionamento assim" (LEÃO, 2016). Esta exigência de tomada de posição é constrangida por uma construção violenta de significados já fechada, que ecoa diversas ações previamente estabelecidas (BLUTER, 1997, p. 51, apud SILVA e ALENCAR, 2014, p. 260), estas, por sua vez, são orientadas para a negação dos sentidos assumidos no horizonte social do blog. Assim sendo, por fim, a intimação, apenas o arremate de uma encenação na qual a infelicidade do ato (AUSTIN, 1990, p. 24; 30-1) de defesa já estava consumada da parte dos 
reclamantes. Por conseguinte, posicionar-se diante do "mulheres de grelo duro" foi mero mote para a contenda de uma outra disputa, isto é, pela legitimidade de dizer sobre o feminismo. Ao entender-se que o poder de ação da linguagem se encontra nas "condições sociais da instituição do ministério que constitui o mandatário legítimo como sendo capaz de agir através das palavras" (BORDIEU, 1998, p. 60, apud ALENCAR, 2014, p. 94), percebe-se o caráter particularmente desagregador deste ato de fala comentador/“Não Me Kahlo”.

O caráter desagregador ocorre através da deliberada tentativa de desautorização da própria legitimidade do blog "Não Me Kahlo". Sabendo que "a eficácia da autoridade do enunciador depende também da sua posição dentro 'dos quadros institucionais e nos ritos sociais"” (AMOSSY, 2005b, p. 119-120, apud GONÇALVES, 2014, p. 313), a situação de impolidez se agrava, porque este blog tem sua gênese dentro da histórica negação e violação da fala de mulheres em nossas relações sociais. Daí a advertência de Leão: "não nos escutam quando falamos nos direitos das mulheres, na configuração sistêmica do machismo, no feminicídio, na morte de mulheres transexuais. O que chama atenção e querem nos ouvir é sobre "grelo duro" ser ofensivo ou não? Me poupe!".

Logo, os sentidos compartilhados nestes atos em nenhum momento foram consensualizados, pelo contrário: antagonismo e violação contextual foram estratégias comuns para sua interconstituição. Podemos concluir que fica evidente o quanto estes atos de fala são pautados pela não contratualidade; e que certamente este não é um ato anômalo, ou incomum das práticas discursivas. Diante do que fica insustentável o argumento do princípio da cooperação de Grice, tal qual ele o pontou, segundo uma visão de mundo liberal, marcado pela implicada naturalização de uma visão de simetria de relações de poder. Explicar os atos impolidos e o contexto de tensão como sendo anomalias de uma suposta cooperação universal concorre, positivamente, como performance científica para a manutenção das mesmas relações hegemônicas de poder. Por se tratar a impolidez como mero acidente, desvio do princípio da cooperação, as práticas marginalizadoras de diversos grupos sociais, orientadas nela, também são tomadas acriticamente como um acidente ingênuo. O que ocorre histórica e violentamente contra a fala dos grupos político-feministas não são meras contingências; são parte de um "projeto" de silenciamento de minorias. Destarte, revisar princípios tradicionais ideológicos linguísticos como o da cooperação é passo essencial da consolidação do caráter político dos estudos críticos da linguagem.

\section{Conclusão}


Neste artigo buscamos fazer coro às vozes e aos corpos e suas héxis (GONÇALVES, 2014, p. 314) que pleiteiam ampliar as fronteiras dos horizontes sociais em que a significação aberta evolui (BAKHTIN/VOLOSHINOV, 2010, p. 140-1), aproximando-nos dos diversos posicionamentos políticos contra-hegemônicos e, de certo modo, desconstrutores em estudos críticos da linguagem (AUSTIN, 1990; BAKHTIN/VOLOSHINOV, 2010; RAJAGOPALAN, 2010; SILVA; MARTINS FERREIRA; ALENCAR, 2014); de modo que pudéssemos reavaliar ideologicamente conceitos conservadores nos estudos da linguagem, críticos e da linguística aplicada, como o princípio da cooperação. Essa trajetória não se basta por si mesma, mas por sua ideologia linguística (BLOMMAERT, 2014) destronizadora, que pode fazer frente a um modelo de organização social monovalente, em cujas raízes estruturais encontra-se a falaciosa crença num mundo pacífico e harmoniosamente feito para o bem-estar comum, bem ao contrário do em que antagonicamente atuamos. Percebemos que, antes de ser uma ocorrência acidental, anômala, ou incomum na interação discursiva, o caráter desagregador do ato de fala polêmica comentador/ "Não Me Kahlo" exemplifica uma forma constitutiva de estabelecer relação de emulação entre os enunciadores. Dessa forma, propomos a crítica do princípio da cooperação, de maneira que se atente para o valor constitutivo da impolidez no discurso. O que traria como ganho esta perspectiva é não perder de vista a particularidade tensa das relações sociais e a vigilância na pesquisa sobre a linguagem dos problemas da marginalização e das assimetrias. A dimensão ética, portanto, estaria presente nos debates sobre a constituição e circulação dos sentidos nas práticas discursivas.

\section{Referências}

ALENCAR Claudiana Nogueira de. Pragmática cultural: uma visada antropológica sobre os jogos de linguagem. In: SILVA, D. N.; MARTINS FERREIRA, D. M. M.; ALENCAR, C. N. (Orgs.) Nova Pragmática: modos de fazer. São Paulo: Cortez, 2014. p. 78-100.

AUSTIN, John Langshaw. Quando dizer é fazer. Trad. de Danilo Marcondes de Souza Filho. Porto Alegre: Artes Médicas: 1990.

BLOMMAERT, J. Ideologias linguísticas e poder. In: SILVA, D. N.; MARTINS FERREIRA, D. M. M.; ALENCAR, C. N. (Orgs.). Nova Pragmática: modos de fazer. São Paulo: Cortez, 2014. p. 67-77. 
BAKHTIN, M. M.; VOLOSHINOV, V. N. Marxismo e filosofia da linguagem. 12. ed. Tradução de Michel Lahud e Yara Frateschi Vieira. São Paulo: HUCITEC, 2010.

EXTRA DIGITAL. http://extra.globo.com/, http://extra.globo.com/noticias/brasil/lula-chamafeministas-do-pt-de-mulheres-do-grelo-duro-internautas-reagem-18897069.html, 11/04/2016.

LEÃO, Bruna. Lula, "grelo duro" e a hipocrisia da direita. http://www.naomekahlo.com/, http://www.naomekahlo.com/\#!Lula-\%E2\%80\%9Cgrelo-duro\%E2\%80\%9D-e-a-hipocrisiada-direita/c1a1n/56f18d0f0cf225c3be494a72, 11/04/2016.

LEEZENBERG, Michiel. Em torno de uma abordagem prática em pragmática: tragédia grega como conversação impolida. In: SILVA, D. N.; MARTINS FERREIRA, D. M. M.; ALENCAR, C. N. (Orgs.) Nova Pragmática: modos de fazer. São Paulo: Cortez, 2014. p. 4368.

MARCONDES, D. A filosofia da linguagem de J. L. Austin. In: AUSTIN, John Langshaw. Quando dizer é fazer. Trad. de Danilo Marcondes de Souza Filho. Porto Alegre: Artes Médicas: 1990. p. 7-17.

MEY, Jacob L. Sequencialidade, contexto e forma lingüística. In: SILVA, D. N.; MARTINS FERREIRA, D. M. M.; ALENCAR, C. N. (Orgs.). Nova Pragmática: modos de fazer. São Paulo: Cortez, 2014. p. 129-144.

RAJAGOPALAN, K. Da arrogância cartesiana à "nova pragmática". In: SILVA, D. N.; MARTINS FERREIRA, D. M. M.; ALENCAR, C. N. (Orgs.). Nova Pragmática: modos de fazer. São Paulo: Cortez, 2014. p. 11-4.

Nova Pragmática: fases e feições de um fazer. São Paulo: Parábola, 2010.

SILVA, Daniel do Nascimento e. ALENCAR, Claudiana Nogueira de. MARTINS FERREIRA, Dina Maria Martins. Uma nova pragmática para antigos problemas. In: SILVA, D. N.; MARTINS FERREIRA, D. M. M.; ALENCAR, C. N. (Orgs.). Nova Pragmática: modos de fazer. São Paulo: Cortez, 2014. p. 15-40.

SILVA, Daniel do Nascimento e; e ALENCAR, Claudiana Nogueira de. Violência e significação: uma perspectiva pragmática. In: SILVA, D. N.; MARTINS FERREIRA, D. M. M.; ALENCAR, C. N. (Orgs.). Nova Pragmática: modos de fazer. São Paulo: Cortez, 2014. p. 259-283.

WITTGENSTEIN, Ludwig. Investigações Filosóficas. São Paulo: Nova Cultural, 1989.

\section{The constitutive principle of impoliteness in language games}

Abstract: In this article, bringing us closer to political positions against hegemonic and deconstructors in critical studies of language, comparing us to the fallacious belief in a peaceful and harmonious world made for the common good, we question the principle of SOLETRAS - Revista do Departamento de Letras da FFP/UERJ 
cooperation Grice, precisely because it involves a vision of liberal world, marked by the consumption of an idea of symmetry of power relations. We have analyzed the online controversy between the Não Me Kahlo blog and a commentator about the expression "women hard grelo" Lula. Fundamented in these authors, concepts and categories: Leezenberg (2014), constitutive impoliteness speech; Rajagopalan $(2010,2014)$, the political nature of language studies; Silva, Alencar Martins and Ferreira (2014), summary of the principle of cooperation; Bloomaert (2014) and Rajagopalan (2014), power and ideology in language; Bakhtin / Voloshnov (2010) ideological chain, social horizente and speech as an arena of ideological struggles; Alencar (2014) and Gonçalves (2014), the institutional developments of the authority of speech acts. Methodologically we criticize consensuality as standard in language games, pointing the denier and coercion character of speech in the studied event. We conclude that the particularly disruptive character of the speech act controversial commentator / Não Me Kahlo exemplifies the emulation between the enunciator and that, in his speech, is not an anomalous act, or unusual. Thus, we argue that the principle of cooperation is not the only basis of the discursive practices of meaning construction and perhaps not be as productive as there are cases where the meaning is disputed resorting to impoliteness in language games.

Keywords: Impoliteness . Linguistic ideology. Discursive practices . Violence. Feminism.

Recebido em: 30 de abril de 2016.

Aprovado em: 14 de julho de 2016. 